\title{
IMPLANTAÇÃO DE UM LABORATÓRIO DE ANÁLISE DA QUALIDADE DA ÁGUA E EFLUENTES DE UMA INDÚSTRIA FARMACÊUTICA
}

\section{IMPLEMENTATION OF AN ANALYSIS LABORATORY FOR WATER AND WASTEWATER QUALITY OF A PHARMACEUTICAL INDUSTRY}

\author{
Letícia Franco $^{1}$; Patrícia Bilotta ${ }^{2}$ \\ ${ }^{1}$ Procytek Soluções Ambientais - Curitiba - Paraaná \\ leticiaf.franco@gmail.com \\ ${ }^{2}$ Universidade Positivo - UP - Curitiba - Paraná \\ pbilotta@up.edu.br
}

\begin{abstract}
Resumo
A água para fabricação de fármacos demanda qualidade rigorosa, por isso requer sucessivas etapas de purificação para atender as determinações da legislação brasileira. Da mesma forma, o efluente gerado no processo produtivo também exige tratamento antes do seu descarte em corpos d'água. O monitoramento da qualidade da água e do efluente industrial é realizado por meio de análises laboratoriais, em muitos casos, por laboratórios terceirizadas a um custo elevado. $O$ objetivo deste artigo é identificar os parâmetros de análise da qualidade da água e efluente de uma indústria do ramo farmacêutico e propor instrumentos analíticos para a implantação de um laboratório analítico. $O$ desenvolvimento da pesquisa se baseou na identificação dos parâmetros de análise da qualidade e na aplicação de metodologias analíticas para água e efluente, considerando a legislação vigente e dados da literatura. Com base nos resultados obtidos, são recomendados os seguintes equipamentos analíticos: agitador magnético com aquecimento, oxímetro, autoclave, capela, condensador, balança analítica, bico de Bunsen, manta de aquecimento, espectrofotômetro, bomba a vácuo, banho-maria, incubadora para teste microbiológico, potenciômetro, estufa, mufla, condutivímetro, extração de Soxhlet, digestor-destilador Kjeldahl, equipamento respirométrico, incubadora (DBO). As vantagens da implantação do laboratório são: redução de custos com terceirização das análises; maior periodicidade das análises e controle do tratamento da água e efluente; prestação de serviço para indústrias que não possuem laboratório (fonte adicional de recursos); reuso de água do processo produtivo; potencial de aproveitamento de água chuva e redução de custos com outorga de captação de água e lançamento de efluentes.
\end{abstract}

Palavras-chave: indicador de qualidade; água industrial; efluente industrial; purificação da água; reuso de água.

\section{Introdução}

O setor farmacêutico é um dos ramos de atividade industrial que responde pelo consumo de grandes volumes de água em seu processo de produção. Além da elevada quantidade de água potável consumida, a qualidade requerida é outro aspecto que merece especial atenção, pois seu impacto nas características do produto final implica em consequências diretas para a saúde humana. 
Sendo assim, tanto a qualidade quanto a quantidade de água utilizada na produção de fármacos deve ser rigorosamente controlada, de modo a atender as necessidades de produção da indústria e as exigências da legislação brasileira, em relação a qualidade do produto final.

$\mathrm{Na}$ prática, qualquer que seja a origem da água utilizada no processo produtivo de fármacos, isto é, água subterrânea (poço artesiano - por exemplo) ou água proveniente de uma estação municipal de tratamento (ETA), será necessário o seu rigoroso tratamento, pois nos dois casos a qualidade da água bruta é inferior à qualidade exigida pela legislação que rege a produção de fármacos (ANVISA, 2010a; ANVISA, 2010b). Por essa razão, para atender aos padrões de qualidade da água de abastecimento industrial, as indústrias farmacêuticas fazem uso de tecnologias e procedimentos diversos, os quais ocorrem na própria indústria em uma área destinada especificamente para esta finalidade.

Assim como a água de abastecimento, o efluente industrial (gerado no processo produtivo) também requer tratamento antes de seu lançamento em corpos d'água, conforme determina a Política Nacional dos Recursos Hídricos (Lei 9.433 - 1997), por meio do Conselho Nacional do Meio Ambiente - CONAMA. Esse fato se explica pela presença de contaminantes incorporados à água ao longo do processo produtivo, os quais modificação as características físicas, químicas e microbiológicas da água e, por sua vez, podem provocar a poluição de rios, lagos e reservatórios superficiais e subterrâneos que receberem o efluente nessas condições.

Além da restrição legal para a qualidade da água bruta e do efluente, nas últimas décadas tem sido crescente o estímulo mundial ao reuso de água, principalmente para fins não potáveis, como é o caso do reuso industrial de água. Embora seja uma prática ainda incipiente no Brasil, a tendência é que nos próximos anos o reuso de água na indústria seja amplamente adotado, devido a fatores como a pressão da legislação ambiental por limites de qualidade de efluentes cada vez mais restritivos, o que implica em tecnologias de tratamento cada vez mais avançadas, a cobrança pelo uso da água (captação) e a cobrança na outorga de lançamento de efluentes em corpos d'água.

Sendo assim, para atender a essas exigências legais e de mercado é forçosamente necessário o monitoramento da qualidade da água tratada consumida no processo industrial e dos efluentes gerados nele, e isso se dá por meio de análises de laboratório, utilizando-se parâmetros físicos, químicos e microbiológicos diversos, que, por sua vez, demandam procedimentos e equipamentos específicos e requerem conhecimento técnico para a sua utilização. Desse modo, a implantação de um laboratório de análise da qualidade da água e efluente de um indústria é elemento indispensável na gestão industrial.

Todavia, não há relatos de publicações e orientações técnicas que auxiliem na realização dessa tarefa, portanto este estudo trás uma grande contribuição na orientação de gestores da área ambiental para a implantação de um laboratório de análise da qualidade da água e de efluentes 
industriais, em particular do setor farmacêutico. A proposta deste trabalho se baseou no levantamento da legislação brasileira vigente, em termos dos padrões e limites de qualidade da água e efluente, e a verificação das práticas de laboratório mais adequadas. Como resultado da pesquisa, foram identificados os parâmetros físicos, químicos e microbiológicos necessários para o monitoramento da qualidade da água e efluente da indústria farmacêutica, bem como foram identificados os métodos de análise para os parâmetros selecionados e foram recomendados os equipamentos analíticos mais adequados para a implantação do laboratório de análise.

\section{Contextualização}

A Lei Federal 9.433 de 1997 estabelece que a água encontrada no território brasileiro, seja em mananciais superficiais ou reservatórios subterrâneos, é um bem público e sua qualidade deve garantir os usos múltiplos previstos na Resolução CONAMA 357 de 2005. São eles: abastecimento doméstico e industrial, irrigação, dessedentação de animais, geração de energia elétrica, preservação da flora e fauna, recreação, navegação, harmonia paisagística e diluição de despejos (BRASIL 1997; CONAMA, 2005). As exigências de qualidade da água são estabelecidas com base na classificação dos cursos d'água e na destinação pretendida. Portanto, quanto mais nobre sua utilização maior será a exigência de qualidade, como é o caso do abastecimento doméstico e industrial, com especificações mais restritivas de qualidade (CONAMA, 2005).

O padrão da água para o consumo humano é definido pelo Ministério da Saúde, regulamentado pela Portaria 2.914 de 2011, enquanto a água utilizada em processos industriais deve atender requisitos de qualidade específicos segundo o ramo da atividade exercida (BRASIL, 2011). Para indústrias farmacêuticas, objeto deste estudo, a Resolução RDC 17 de 2010 estabelece boas práticas para produção de medicamentos no país. A Agência Nacional de Vigilância Sanitária (ANVISA) também estabelece padrões e limites de qualidade para a água utilizada na produção de fármacos, na manipulação e síntese de medicamentos, testes laboratoriais ou higienização de utensílios e equipamentos (ANVISA, 2010a; ANVISA, 2010b).

Os contaminantes mais comuns em água bruta são: material particulado (compostos orgânicos e inorgânicos) e microrganismos diversos. A maioria dos compostos orgânicos pode ser removida por mecanismos de barreira, como osmose reversa, já a remoção de compostos inorgânicos requer técnicas adicionais de tratamento avançado, como resina de troca iônica, carvão ativado e sistemas de membrana de alta capacidade de retenção de sólidos, enquanto que os métodos mais utilizados para remoção de microrganismos são ozônio, radiação ultravioleta e membranas (nanofiltração e ultrafiltração) (BRAILE e CAVALCANTI, 1993; WEBER e LEBOEUF, 1999; MARTINS, 2001; MELTZERM et al, 2003; DI BERNARDO e DANTAS, 2005; ANVISA, 2010b; BOLEDA, 2011). 
A água destinada à síntese de produtos ativos e para a operação de certos equipamentos necessita de permanente monitoramento, para atender a legislação vigente (MARTINS, 2001; ULTRAMARI, 2005; ANVISA, 2010a; ANVISA, 2010b). A água resultante do processo produtivo juntamente com o esgoto gerado nas atividades humanas (pia do refeitório, limpeza do piso, vaso sanitário, etc) constituem o efluente industrial. Como o efluente final possui características que põem em risco a saúde humana e a qualidade ambiental, a legislação brasileira exige seu tratamento antes do descarte em corpos d'água (CONAMA, 2005; CONAMA, 2011).

Em muitos casos, o tratamento do efluente ocorre na própria indústria, em estações de tratamento projetadas para remover os contaminantes diversos que excedem os limites máximos estabelecidos na legislação brasileira, para o lançamento em corpos d'água, ou que ultrapassem os limites determinados pelas companhias de saneamento para descarte do efluente nas redes coletoras de esgoto do município. As alternativas de tratamento mais utilizadas são: processos físicos (gradeamento, sedimentação, flotação, medição de vazão), processos químicos (coagulação seguida de floculação, oxidação química, precipitação química) e processos biológicos (reatores biológicos, filtros biológicos e lagoas de estabilização - aeróbios ou anaeróbios) (BRAILE e CAVALCANTI, 1993; GOHARY et al, 1995; BURTON et al, 2002; METCALF e EDDY, 2003; KLEMES, 2012).

Porém, tanto o tratamento da água de alimentação do processo produtivo industrial quando o tratamento do efluente demanda monitoramento contínuo para garantir, em cada caso, a eficiência e qualidade final desejada. Assim, a adequada infraestrutura do laboratório de análise é primordial para a caracterização qualitativa e quantitativa da água consumida e do efluente gerado e para se monitorar o desempenho dos sistemas de tratamento.

As vantagens da implantação do laboratório na indústria são: a) redução de custos com terceirização das análises, de modo geral onerosas; b) maior regularidade entre as análise; c) maior capacidade de interferir no processo de tratamento quando alterações são identificadas com frequência; d) possibilidade de prestação de serviços para outras indústrias de menor porte que não possuem instalações de laboratório. O reuso de água do processo produtivo e o aproveitamento de água de chuva também têm sido práticas comuns no setor industrial, o que também requer o monitoramento da qualidade da água e do efluente tratado (METCALF e EDDY, 2003; KLEMES, 2012; TONG et al, 2013). Sendo assim, a implantação de um laboratório de análises oferece benefícios diretos e indiretos para a indústria em todos os sentidos.

\section{Metodologia}

A pesquisa foi dividida em duas etapas: 1) água de abastecimento; 2) efluente. Em cada etapa foram verificadas as legislações vigentes, em termos de padrões e limites de qualidade 
aceitáveis, e foram identificados os procedimentos de análise mais adequados. O estudo de caso foi realizado em uma indústria de fitoterápicos de médio porte, localizada na região metropolitana de Curitiba/PR, a qual utiliza como matéria-prima caule, folhas e raízes de plantas, extratos vegetais, água, álcool, xarope de sacarose, excipientes farmacêuticos, dentre outros componentes de menor proporção.

\subsection{Etapa 1: água de abastecimento industrial}

A água utilizada pela indústria em estudo é captada diretamente de um poço artesiano e atende $99 \%$ da sua demanda. Aproximadamente $20 \mathrm{~m}^{3}$ diários de água são utilizados na área industrial, sendo que $180 \mathrm{~L} / \mathrm{h}$ são destinados ao processo produtivo e o restante para as demais atividades humanas (refeitório, banho, sanitário, limpeza, etc). Na purificação da água a indústria utiliza o processo de deionização, que consiste na remoção de sólidos finamente dissolvidos, como íons e sais minerais, e a desinfecção com radiação UV, comercialmente denominadas lâmpadas germicidas, para a inativação de microrganismos.

A água bombeada do poço artesiano com destino aos processos industriais passa previamente pela cloração (pré-desinfecção) e, em seguida, pela deionização e pelas lâmpadas UV. A água consumida nas atividades humanas (refeitório, limpeza e higiene pessoal) passa apenas pela etapa de cloração inicial, para o controle de microrganismos patogênicos, como determina o Ministério da Saúde. Como a qualidade da água subterrânea captada pela indústria está de acordo com os limites da legislação, não é necessário nenhum outro tratamento adicional. Os pontos de amostragem para o monitoramento da qualidade da água se localizam na saída do deionizador e na saída do reator UV.

\subsection{Etapa 2: efluente da indústria}

A indústria farmacêutica em estudo possui uma estação de tratamento de efluentes, denominada ETEI, composta por tratamento físico-químico seguido por tratamento biológico. A seguinte sequência de unidades de tratamento compõe a ETEI em questão:
a) Gradeamento (recebe o efluente industrial);
b) Caixa de gordura;
c) Tanque de equalização 1 ;
d) Tanque de coagulação;
e) Tanque de floculação;
f) Decantador;
g) Tanque de equalização 2 (recebe o esgoto sanitário);
h) Reator biológico (lodos ativados); 
i) Lagoa 1;

j) Lagoa 2;

k) Lagoa 3 (saída para o corpo hídrico).

O tratamento físico-químico é composto por gradeamento (para remoção de sólidos grosseiros) e caixa de gordura (para remoção de óleos e graxas), em seguida o efluente é conduzido para um tanque de equalização, para a homogeneização do efluente e equalização da vazão, e depois segue para a etapa de coagulação/floculação, onde se inicia a clarificação do efluente (remoção de sólidos suspensos e dissolvidos). Então, o efluente segue para o decantador, para promover a separação sólido-líquido (clarificação do efluente), e depois para um outro tanque equalizador, que recebe agora o esgoto sanitário. Essa mistura é encaminhada para um reator biológico de lodos ativados convencional (para remoção da carga orgânica, nitrogênio e fósforo). Por fim, o efluente passa por duas lagoas de polimento e uma lagoa facultativa (para remoção da carga orgânica remanescente, de nutrientes e inativação de microrganismos). O tempo de detenção hidráulica (TDH) entre as lagoas é de 30 horas.

O efluente gerado na indústria farmacêutica é considerado de fácil tratabilidade, pois grande parcela dos resíduos da fabricação dos medicamentos são retidos antes de serem encaminhados à estação de tratamento.

\subsection{Seleção dos instrumentos de análise}

A escolha dos instrumentos analíticos, recomendados para o laboratório de análises, se baseou em exames preliminares da qualidade da água e efluente da indústria investigada, como estudo de caso, e na verificação da legislação brasileira vigente. Os parâmetros físicos, químicos e microbiológicos foram quantificados de acordo com as metodologias mais utilizadas na análise da qualidade da água e de efluentes, conforme o manual Standard methods for the examination of water and wastewater, publicado pela APHA (1998), e outras literaturas científicas relevantes para o assunto abordado (BURTON et al, 2002; DI BERNARDO e DANTAS, 2005; VON SPERLING, 2005; MACEDO, 2007).

\section{Resultados e discussões}

\subsection{Análise da qualidade da água}

De acordo com a descrição apresentada na metodologia, a água utilizada pela indústria neste estudo de caso pode ser dividida em duas categorias principais: 1) água potável para consumo humano; 2) água purificada utilizada para o abastecimento industrial. A água na categoria 1 deve obedecer aos padrões de qualidade estabelecidos pelo Ministério da Saúde, por meio da Portaria 2.914 de 2011, isto é, deve seguir as diretrizes indicadas pelo padrão de potabilidade (BRASIL, 
2011). Segundo essa legislação, em se tratando de captação de água subterrânea para consumo humano é recomendado os seguintes parâmetros de análise de qualidade: coliformes totais e coliformes termotolerantes.

A água destinada à categoria 2 deve atender aos padrões de qualidade definidos pela ANVISA, por meio da Resolução RDC 49 de 2010 (ANVISA, 2010b), pois nesse caso a água será utilizada como matéria-prima no processo de fabricação de fármacos e, dessa forma, deve apresentar elevado grau de pureza, isto é, deve estar acima do padrão de potabilidade para garantir a adequada qualidade do produto final. Os parâmetros de análise da qualidade recomendados para a categoria 2 são: dureza total, cálcio, magnésio, condutividade elétrica, resíduos de evaporação, cloro residual, $\mathrm{pH}$, sólidos dissolvidos totais (SDT), cloreto, sulfato, nitrato, alcalinidade, coliformes totais e coliformes termotolerantes.

A partir dos parâmetros relacionados acima pode-se identificar a necessidade dos seguintes instrumentos analíticos: agitador magnético com aquecimento, condensador, balança analítica, bico de Bunsen, manta de aquecimento, espectrofotômetro, autoclave, banho-maria, incubadora para testes microbiológicos, potenciômetro e condutivímetro. Para a indicação dos equipamentos listados acima foram consideradas as metodologias descritas pela principal bibliografia mundial de análises da qualidade da água e efluentes - Standard Methods for the Examination of Water and Watewater (APHA, 1998).

\subsection{Análise da qualidade do efluente}

Atualmente a indústria em estudo realiza apenas coletas para a análise mensal da qualidade do efluente final na saída da ETEI, de modo a fornecer informações para o órgão ambiental estadual. Portanto, não são realizadas análises de monitoramento do desempenho e eficiência do tratamento físico, químico e biológico do efluente ao longo da ETEI. A indústria deve atender os critérios e padrões de emissão de poluentes estabelecidos nas Resoluções CONAMA 357/2005 e CONAMA 430/2011, regulamentadas pelo Ministério do Meio Ambiente, assim como respeitar os parâmetros de qualidade definidos na Licença de Operação emitida pelo Instituto Ambiental do Paraná, órgão responsável pelo licenciamento ambiental de atividades potencialmente poluidoras no estado. Sendo assim, os parâmetros físicos, químicos e microbiológicos recomendados para a análise da qualidade do efluente são: $\mathrm{pH}$, demanda química de oxigênio (DQO), demanda bioquímica de oxigênio (DBO), óleos e graxas, sólidos sedimentáveis (SS), sólidos totais (ST), sólidos totais fixos (STF), sólidos totais voláteis (STV), sólidos suspensos totais (SST), sólidos suspensos fixos (SSF) e sólidos suspensos voláteis (SSV), nitrogênio total, fósforo total e surfactantes. 
Com base nos resultados obtidos nessa análise, são recomendados os seguintes instrumentos analíticos para a verificação da qualidade do efluente: aparelho de extração de Soxhlet, autoclave, balança analítica, bico de Bunsen, bomba de vácuo, capela, condensador, digestor-destilador de Kjeldahl, equipamento respirométrico, espectrofotômetro, estufa de secagem, incubadora de DBO, manta de aquecimento, mufla, agitador magnético com aquecimento, potenciômetro e oxímetro. Para a indicação dos equipamentos listados acima foram consideradas as metodologias descritas pela principal bibliografia mundial de análises da qualidade da água e efluentes - Standard Methods for the Examination of Water and Watewater (APHA, 1998).

\subsection{Instrumentos analíticos recomendados}

A Tabela 1 sintetiza a lista de parâmetros de análise da qualidade da água para consumo humano e abastecimento industrial e do efluente gerado pela indústria farmacêutica em estudo, bem como relaciona os respectivos métodos de análise mais utilizados. Os parâmetros foram selecionados segundo as metodologias mais utilizadas para a verificação da qualidade da água e de efluentes, conforme publicação da Standard Methods for the Examination of Water and Watewater (APHA, 1998) e com base em consulta a outras literaturas relevantes (BURTON et al, 2002; DI BERNARDO e DANTAS, 2005; VON SPERLING, 2005; MACEDO, 2007).

Tabela 1 - Relação dos parâmetros de verificação da qualidade da água e do efluente da indústria em estudo e identificação dos procedimentos analíticos recomendados

\begin{tabular}{|c|c|c|c|}
\hline \multicolumn{2}{|c|}{ Qualidade da Água } & \multicolumn{2}{|c|}{ Qualidade do Efluente } \\
\hline Parâmetros & Método de análise & Parâmetros & Método de análise \\
\hline $\begin{array}{c}\text { Dureza total } \\
\text { Cálcio } \\
\text { Magnésio } \\
\text { Condutividade } \\
\text { Cloro residual } \\
\text { Sólidos Dissolvidos Totais } \\
\text { Cloreto } \\
\text { Sulfato } \\
\text { Nitrato } \\
\text { Alcalinidade } \\
\text { Coliformes totais } \\
\text { Coliformes termotolerantes } \\
\text { pH }\end{array}$ & $\begin{array}{c}\text { Titulometria } \\
\text { Titulometria } \\
\text { Titulometria } \\
\text { Eletrometria } \\
\text { Iodometria } \\
\text { Gravimetria } \\
\text { Titulometria } \\
\text { Gravimetria } \\
\text { Gravimetria } \\
\text { Titulação potenciométrica } \\
\text { Contagem de placas } \\
\text { Contagem de placas } \\
\text { Potenciometria }\end{array}$ & $\begin{array}{c}\text { Demanda Química de Oxigênio } \\
\text { Demanda Bioquímica de Oxigênio } \\
\text { Óleos e graxas } \\
\text { Sólidos Suspensos } \\
\text { Sólidos Totais } \\
\text { Sólidos Totais Fixos } \\
\text { Sólidos Totais Voláteis } \\
\text { Sólidos Suspensos Totais } \\
\text { Sólidos Suspensos Fixos } \\
\text { Sólidos Suspensos Voláteis } \\
\text { Nitrogênio total } \\
\text { Fósforo total } \\
\text { Surfactantes } \\
\text { pH }\end{array}$ & $\begin{array}{c}\text { Refluxo aberto } \\
\text { Teste } \text { DBO }_{5,20} \\
\text { Soxhlet } \\
\text { Gravimetria } \\
\text { Gravimetria } \\
\text { Gravimetria } \\
\text { Gravimetria } \\
\text { Gravimetria } \\
\text { Gravimetria } \\
\text { Gravimetria } \\
\text { Kjeldahl } \\
\text { Fósforo solúvel } \\
\text { Extração solvente } \\
\text { Potenciometria }\end{array}$ \\
\hline
\end{tabular}

Fonte: Autoria própria (2013)

A partir das informações relacionadas na Tabela 1, foi elaborada uma lista com os equipamentos mais adequados para cada análise e metodologia utilizada. Como resultado, a Tabela 2 relaciona os instrumentos analíticos que devem compor o laboratório de verificação da qualidade da água de abastecimento industrial e do efluente gerado no processo produtivo. 
Tabela 2 - Instrumentos analíticos recomendados para a indústria em estudo

\begin{tabular}{c}
\hline Equipamentos Necessários \\
\hline Análise da Água/Análise do Efluente \\
\hline Espectrofotômetro \\
Incubadora de DBO \\
Equipamento de respirometria \\
Condensador \\
Digestor-destilador Kjeldahl \\
Balança analítica \\
Incubadora para testes microbiológicos \\
Aparelho de extração de Soxhlet \\
Manta elétrica de aquecimento \\
Bomba de Vácuo \\
Potenciômetro \\
Oxímetro \\
Agitador magnético com aquecimento \\
Mufla e estufa de secagem \\
Bico de Bunsen \\
Condutivímetro \\
Banho-maria \\
Capela \\
Autoclave
\end{tabular}

Fonte: Autoria própria (2013)

Vários instrumentos analíticos recomendados (Tabela 2) são utilizados tanto para análises de qualidade da água quanto do efluente, respeitadas as devidas especificações técnicas definidas pelos fabricantes. Além disso, alguns instrumentos analíticos possibilitam ainda a interpretação de dois ou mais parâmetros simultaneamente, como é o caso do espectrofotômetro, da estufa e da mufla, os quais podem ser compartilhados na análise de diferentes parâmetros de qualidade.

\subsection{Benefícios diretos e indiretos da implantação do laboratório}

A qualidade da água consumida pelo setor industrial e do efluente gerado no processo produtivo demandam monitoramento contínuo para se avaliar a eficiência e o desempenho dos sistemas de tratamento e garantir, assim, a qualidade final requerida pela legislação ambiental brasileira.

O custo das análises de monitoramento da qualidade da água e do efluente varia de acordo com os parâmetros analisados, a quantidade de amostras (e repetições) e a periodicidade das coletas. Quando a indústria possui um laboratório próprio para a realização dessas análises alguns aspectos passam a contar positivamente na relação custo / benefício, são eles: redução de custos com a terceirização das análises (geralmente bastante onerosas, pois incluem o custo laboratorial mais o lucro da atividade); otimização da periodicidade e regularidade entre as análises (redução do intervalo de tempo entre as coletas mensais); maior capacidade de controle do processo de tratamento da água e do efluente (permite a identificação do problema através das análises e a intervenção imediata quando necessário); possibilita a prestação de serviço para outras indústrias de médio e pequeno porte (inclusive de outros ramos de atividade) que não possuem instalações de laboratório, representando uma fonte adicional de recursos para a indústria; possibilidade de reuso 
de água proveniente do processo produtivo (resultado do monitoramento contínuo e verificação da qualidade do efluente); aproveitamento de água chuva como medida de redução de custos com a cobrança pelo uso da água (captação) e a outorga de lançamento de efluentes (BRASIL, 1997).

Ações como o reuso de água veem de encontro às diretrizes da sustentabilidade, gerando benefícios ambientais diretos, em razão da redução do consumo de água limpa de cursos d'água, além de benefícios econômicos para a indústria, bem como estão alinhadas aos processos antrópicos de adaptação às mudanças climáticas, no tocante aos recursos hídricos, conforme relatório do IPCC - Intergovernmental Panel on Climate Change (PARRY et al, 2007).

Deve-se destacar também a importância do levantamento detalhado e minucioso das vidrarias utilizadas e dos produtos químicos necessários para a realização dos procedimentos indicados na Tabela 1, assim como a adequada preparação das soluções e armazenamento dos reagentes utilizados. Sem esses cuidados os equipamentos podem fornecer resultados imprecisos e de baixa confiabilidade. Finalmente, estudos complementares são sugeridos para se estabelecer também o custo total da aquisição dos equipamentos recomendados neste trabalho, bem como o tempo de retorno econômico.

\section{Conclusões}

A qualidade da água utilizada na indústria farmacêutica deve atender as determinações da Portaria 2.914/2011, em relação ao consumo humano, e a Resolução RDC 49/2010, para o fornecimento de água ao processo industrial. O efluente após tratamento deve atender aos padrões e limites de qualidade requeridos pelas Resoluções CONAMA 357/2005 e CONAMA 430/2011, bem como as especificações estabelecidas na Licença de Operação do empreendimento emitida pelo órgão ambiental estadual.

Os parâmetros físicos, químicos e microbiológicos recomendados para as análises de qualidade da água (consumo humano e processo produtivo) e do efluente da indústria são: dureza total, cálcio, magnésio, condutividade elétrica, resíduos de evaporação, cloro residual, pH, sólidos dissolvidos totais (SDT), cloreto, sulfato, nitrato, alcalinidade, coliformes totais e coliformes termotolerantes, demanda química de oxigênio (DQO), demanda bioquímica de oxigênio (DBO), óleos e graxas, sólidos sedimentáveis (SS), sólidos totais (ST), sólidos totais fixos (STF), sólidos totais voláteis (STV), sólidos suspensos totais (SST), sólidos suspensos fixos (SSF), sólidos suspensos voláteis (SSV), nitrogênio total, fósforo total e surfactantes.

Com base no estudo de caso investigado, é possível concluir que os instrumentos necessários para a realização de análises de monitoramento da qualidade da água e do efluente são: aparelho de extração de Soxhlet, autoclave, balança analítica, bico de Bunsen, mufla, bomba de vácuo, capela, condensador, digestor-destilador de Kjeldahl, equipamento de respirometria, 
espectrofotômetro, estufa de secagem, incubadora (para os testes de DBO), manta de aquecimento, agitador magnético com aquecimento, oxímetro e potenciômetro. Alguns desses instrumentos podem ser utilizados tanto no monitoramento da qualidade da água quanto do efluente, respeitadas as especificações técnicas dos fabricantes, o que reduz o custo de aquisição de equipamentos para a implantação do laboratório.

Além disso, os instrumentos analíticos indicados neste trabalho permitem a realização de análises de monitoramento da eficiência do tratamento do efluente visando o reuso de água na própria indústria, para fins não potáveis, bem como permite a verificação da qualidade da água de chuva (bruta e tratada) com vistas ao seu reaproveitamento.

\begin{abstract}
Water for drug production demands rigorous quality, although it requires successive purification steps to meet the determinations of the Brazilian regulation. In the same way, the effluent from the production process also requires treatment before its disposal in watercourses. The monitoring of water and industrial wastewater quality is promoted by laboratory analyzes, in many cases it is carried by laboratories out of the industry with a high cost. The aim of this paper is identify parameters for analyzing water and wastewater quality from a pharmaceutical industry and propose analytic instruments to install an analytical laboratory. The development of the research was based into identifying analysis parameters and the application of analytical methodology for water and wastewater, considering the actual regulation and data from literature. Based on results obtained, the following analytical instruments are recommended: magnetic stirrer with heating, oximeter, autoclave, laboratory exhaust-hood, condenser, analytical balance, Bunsen burner, heating mantle, spectrophotometer, vacuum pump, water bath, incubator (microbiology), potentiometer, high temperature furnace, laboratory oven, conductivity, Soxhlet extraction, digester-distiller Kjeldahl, respirometric equipment, incubator (COD). The advantages of installing the laboratory are: cost reducting with analyses outside the industry; greater frequency of analysis and control of the water and wastewater treatment (immediate action when necessary); service offering to industries which do not have laboratory; reuse of water from production process; potencial use of rainwater; cost reduction with water catchment and effluent disposal.
\end{abstract}

Key words: quality indicator; industrial water; industrial effluent; water purification; water reuse.

\title{
Referências
}

ANVISA,. Agência Nacional de Vigilância Sanitária, Resolução RDC n. 17, de 16 de abril de 2010. Dispõe sobre boas práticas de fabricação de medicamentos no Brasil. Disponível em: <http://www.respostatecnica.org.br/dossietecnico/downloadsDT/NTY0Nw==>. Acesso em: 26 set. 2012.

ANVISA b. Agência Nacional de Vigilância Sanitária, Resolução RDC n. 49, de 23 de novembro de 2010. Dispõe sobre a aprovação da Farmacopeia Brasileira, 5. edição e dá outras providências. Disponível em: <http://www.anvisa.gov.br/hotsite/cd_farmacopeia/pdf/volume1.pdf>. Acesso em: 08 dez. 2012.

APHA. Standard methods for the examination of water and wastewater. 19 ed. New York. 1268p, 1998.

BOLEDA, M. R.; GALCERAN, M. T.; VENTURA, F. Behavior of pharmaceuticals and drugs of abuse in a drinking water treatment plant (DWTP) using combined conventional and ultrafiltration and reverse osmosis (UF/RO) treatments. Environmental Pollution, v. 159, n. 6, p. 1584-1591, 2011. crossref 
BRAILE, P. M., CAVALCANTI, J. E. Manual de tratamento de águas residuárias industriais. 2 ed. São Paulo: CETESB, 764p, 1993

BRASIL. P. N. R. H., Lei 9.433, de 08 de janeiro de 1997. Institui a Política Nacional de Recursos Hídricos, cria o Sistema Nacional de Gerenciamento de Recursos Hídricos e dá outras providências. Disponível em: <http://www.planalto.gov.br/ccivil_03/leis/L9433.htm>. Acesso em: 18 set. 2012.

BRASIL. Ministério da Saúde, Portaria 2.914, de 12 de dezembro de 2011. Dispõe sobre os procedimentos de controle e de vigilância da qualidade da água para consumo humano e seu padrão de potabilidade. Disponível em: <http://bvsms.saude.gov.br/bvs/saudelegis/gm/2011/prt2914_12_12_2011.html>. Acesso em 20 set. 2012.

BURTON, F. L., STENSEL, H. D., TCHOBANOGLOUS, G. Wastewater engineering: treatment and reuse. 4 ed. New York: McGraw-Hill's, 630p, 2002.

CONAMA. Conselho Nacional de Meio Ambiente, Resolução 357, de 17 de março de 2005. Dispõe sobre a classificação dos corpos de água e diretrizes ambientais para o seu enquadramento, bem como estabelece condições e padrões de lançamento de efluentes, e dá outras providências. Disponível em: <http://www.mma.gov.br/port/conama/res/res05/res35705.pdf>. Acesso em 19 set. 2012.

CONAMA. Conselho Nacional de Meio Ambiente, Resolução 430, de 13 de maio de 2011. Dispõe sobre as condições e padrões de lançamento de efluentes, complementa e altera a Resolução 357, de 17 de março de 2005. Disponível em: <http://www.mma.gov.br/port/conama/legiabre.cfm?codlegi=646>. Acesso em 19 set. 2012.

DI BERNARDO, L.; DANTAS, A. B. Métodos e técnicas de tratamento de água. 2 ed. São Carlos: RIMA, 792p, 2005.

GOHARY, F. A.; ABOU-ELELA, S. I.; ALY, H. I. Evaluation of biological technologies for wastewater treatment in the pharmaceutical industry. Water Science and Technology, v. 32, n. 11, p. 13-20, 1995. crossref

PARRY, M. L.; CANZIANI, O. F.; PALUTIKOF, J. P.; VAN DER LINDEN, P. J.; HANSON, C. E. Climate change 2007: impacts, adaptation and vulnerability. Contribution of working group II to the fourth assessment report of the Intergovernmental Panelo n Climate Change. Cambridge University Press, Cambridge, UK, 976p, 2007. Disponível em: <http://www.ipcc.ch/publications_and_data/publications_ipcc_fourth_assessment_report_wg2_report_impacts_adaptati on_and_vulnerability.htm>. Acesso em: 08 mai. 2013.

MACEDO, J. A. B. Métodos laboratoriais de análises físico-químicas e microbiológicas. 2 ed. Belo Horizonte: Macêdo, 440p, 2003.

MARTINS, A. M. S. Tratamento de água na indústria farmacêutica. 2001. 212f. Dissertação (Mestrado em Tecnologia Químico-farmacêutica) - Faculdade de Ciências Farmacêuticas da Universidade de São Paulo, São Paulo, 2001.

MELTZERM, T. H.; JORNITZ, M. W.; TETZLAFF, R. F. Regulatory concers regarding filters in pharmaceutical water systems. Pharmaceutical Science \& Technology, v. 57, n. 4, p. 239-244, 2003.

METCALF e EDDY, Inc. Wastewater engineering: treatment and reuse. 4. Ed/revised by George Tchobanoglous, Franklin L., Burton H., David Stensel, New Tork: McGraw-Hill, 2003.

TONG, L.; LIU, X.; LIU, X.; YUAN, Z.; ZHANG, Q. Life cycle assessment of water reuse systems in an industrial park. Journal of Environmental Management, v. 129, n. 15, p. 471-478, 2013. crossref

ULTRAMARI, M. T. Produção, validação e controle de sistemas de purificação de água para injetáveis. 2005. Monografia (Especialização em Gestão da Qualidade na Produção de Alimentos, Medicamentos e Cosméticos) Programa de Qualidade na Produção de Alimentos, Medicamentos e Cosméticos, Pontifícia Universidade Católica do Paraná, Curitiba, 2005.

WEBER, J. R; W. J.; LEBOEUF, E. J. Processes for advanded treatment of water. Water Science and Technology, v. 40, n. 4-5, p. 11-19, 1999. crossref

VON SPERLING, M. Introdução à qualidade das águas e ao tratamento de esgotos. 2 ed. Belo Horizonte: UFMG, 452 p, 2005. 


\section{Dados das autoras}

Nome completo: Letícia Franco

Filiação institucional: Procytek Soluções Ambientais

Departamento: Tratamento de efluentes industriais

Função ou cargo ocupado: Responsável técnica em estações de tratamento de efluentes

Endereço completo para correspondência (bairro, cidade, estado, país e CEP): Rua Prof. Pedro Viriato Parigot de Souza, n. 5300, Bairro Campo Comprido, Curitiba, Paraná

Telefones para contato: (41) 3317-3000

e-mail: leticiaf.franco@gmail.com

Nome completo: Patrícia Bilotta (autor correspondente)

Filiação institucional: Universidade Positivo - UP - Curitiba - Paraná

Departamento: Programa de Mestrado e Doutorado em Gestão Ambiental (PGAMB)

Função ou cargo ocupado: Professora doutora titular da pós-graduação nas áreas de sistemas de tratamento de efluentes, reuso de água e mudanças climáticas (projetos de baixa emissão de carbono e inventários de gases de efeito estufa - GEEs).

Endereço completo para correspondência (bairro, cidade, estado, país e CEP): Rua Prof. Pedro Viriato Parigot de Souza, n. 5300, Bairro Campo Comprido, Curitiba, Paraná, CEP: 81280-330

Telefones para contato: (41) 3317-3460

e-mail:pbilotta@up.edu.br

Submetido em: 10/09/2013

Aceito em: 18/10/2014 